\title{
p53 and telomerase control rat myocardial tissue response to hypoxia and ageing
}

\author{
A. Cataldi, ${ }^{1,2}$ S. Zara, ${ }^{1,2}$ M. Rapino, ${ }^{1}$ M. Zingariello, ${ }^{1}$ V. di Giacomo, ${ }^{1,2}$ A. Antonucci ${ }^{1}$ \\ ${ }^{1}$ Dipartimento di Biomorfologia, ${ }^{2}$ Cattedra di Anatomia Umana, Facoltà di Farmacia, Università \\ G. d'Annunzio, Chieti-Pescara; Istituto di Genetica Molecolare del CNR, Chieti, Italy
}

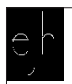

(C)2009 European Journal of Histochemistry

Cellular senescence implies loss of proliferative and tissue regenerative capability. Also hypoxia, producing Reactive Oxygen Species (ROS), can damage cellular components through the oxidation of DNA, proteins and lipids, thus influencing the shortening of telomeres.

Since ribonucleoprotein Telomerase (TERT), catalyzing the replication of the ends of eukaryotic chromosomes, promotes cardiac muscle cell proliferation, hypertrophy and survival, here we investigated its role in the events regulating apoptosis occurrence and life span in hearts deriving from young and old rats exposed to hypoxia.

TUNEL (terminal-deoxinucleotidyl -transferase- mediated dUTP nick end-labeling) analysis reveals an increased apoptotic cell number in both samples after hypoxia exposure, mainly in the young with respect to the old. TERT expression lowers either in the hypoxic young, either in the old in both experimental conditions, with respect to the normoxic young. These events are paralleled by p53 and HIF-1 $\alpha$ expression dramatic increase and by p53/ HIF-1 $\alpha$ co-immunoprecipitation in the hypoxic young, evidencing the young subject as the most stressed by such challenge. These effects could be explained by induction of damage to genomic DNA by ROS that accelerates cell senescence through p53 activation. Moreover, by preventing TERT enzyme down-regulation, cell cycle exit and apoptosis occurrence could be delayed and new possibilities for intervention against cell ageing and hypoxia could be opened.

Key words: p53, telomerase, hypoxia, ageing, rat heart.

Correspondence: Amelia Cataldi

Dipartimento di Biomorfologia, Via dei Vestini 6, 66100 Chieti, Italy

Tel.: 39.0871.3554508.

Fax: 39.0871-.3554568.

E-mail: cataldi@unich.it

Paper accepted on September 18, 2009

European Journal of Histochemistry 2009; vol. 53 issue 4 (October-December): 209-216
0 ellular senescence might cause or contribute to ageing phenotypes owing to a loss of cell proliferative (and tissue regenerative) capability (Ben Porath and Weinberg 2004-2005). In particular myocardial ageing may result from attenuated turnover of myocytes and accumulation of older cells (Torella et al.,2004). Also hypoxia, low oxygen tension, by producing ROS, can damage cellular components through the oxidation of DNA, proteins and lipids, and, by regulating cell growth and survival, can be involved in the occurrence of multiple physiological and pathological processes in the body (Semenza, 2004). In such responses telomere shortening can be involved. Telomeres are specialized DNA-protein complexes which prevent linear chromosome ends from fusion (end to end joining) and from being sensed as a DNA strand break which triggers growth arrest and other responses (Blackburn,2000). Telomere shortening is largely caused by a telomere-specific DNA single-strand break repair inefficiency (Passos et al., 2007). The enzyme involved in replication of the ends of eukaryotic chromosomes (capping) is the ribonucleoprotein TERT (Blackburn, 2001; Rubio et al.,2004). TERT balances terminal DNA losses by lengthening the ends of eukaryotic telomeric DNA through RNA-template addition of tandemly repeated telomeric sequences. If capping does not occur, the response of the cell is exit from the cell cycle, or, in certain mammalian cells, apoptosis. Thus telomere shortening appears to be a biomarker of ageing and is also involved in the response to some oxidative stresses such as hypoxia (McEachern, 2000; Von Zglincki, 2002; Passos et al.,2007). Moreover in cardiac myocytes TERT activity has been observed to delay cell cycle exit, to induce hypertrophy in post-mitotic cells and to promote cell survival ( $\mathrm{hh}$ et al., 2001-2002). In addition, the transcription factor p53, besides to mediate apoptosis occur- 
rence in response to diverse stimuli such as hypoxia, DNA damage, oxidative stress, by trans-activating the expression of multiple pro-apoptotic genes including Bax, Bid, Apaf-1, caspase 6 and Fas (Fridman and Lowe, 2003; Crow et al., 2004) and to play a pivotal role in controlling senescence occurrence, being cellular senescence considered a tumour suppressive mechanism (Sager, 1991; Amundson et al.,1998; Itahana et al., 2001; Torella et al., 2004), is an important sensor of functional telomeres (Smogorzewska and de Lange, 2002; Sharpless and De Pinho, 2004). In light of such evidences here we investigated TERT involvement in the events which regulate both apoptosis occurrence after hypoxia exposure and during ageing in rat myocardial tissue in parallel to p53 and HIF-1 $\alpha$ response.

\section{Materials and Methods}

\section{Animals}

Two groups, each composed by 10 male Wistar rats, $3(250-300 \mathrm{~g})$ and $24(400-450 \mathrm{~g})$ months old, were used according to the guidelines of Principle of Laboratory Animal Care and of Helsinki Declaration as well as of Local Ethical Committee. Only animals free of acute and chronic illness were employed. Five animals from each group were kept under physiological conditions; five young and five old were exposed to intermittent hypoxic challenge ( $12 \mathrm{~h} 10 \% \quad \mathrm{O}_{2}$ followed by $12 \mathrm{~h}$ $21 \% 02 ;$ p 0276 Torr of oxygen) for 8 days in a large plexiglass chamber (cm $80 \times 40 \times 65$ ). Chamber air was re-circulated with a pump, $\mathrm{CO}_{2}$ was removed from the chamber air with baralyme and was continuosly monitored with a capnograph. Boric acid was mixed with the litter to minimize emission of urinary ammonia. The temperature was maintained at $25^{\circ} \mathrm{C}$. (Rapino et al., 2005). Rats were anaesthesized with Pentobarbital sodium salt (Nembutal, 40 $\mathrm{mg} / \mathrm{kg}$ ) (Sigma-Aldrich, St. Louis, Mi, USA) and left ventricles were excised from each rat and processed for experiments.

\section{Morphological analysis}

Small pieces of left ventricles, collected with care, were fixed in $2.5 \%$ glutaraldehyde in $0.1 \mathrm{~mol} / \mathrm{L}$ cacodylate buffer $\mathrm{pH} 7.6$ for $4 \mathrm{~h}$ at $4^{\circ} \mathrm{C}$. Semithin sections ( $1 \mu \mathrm{m}$ ) were Toluidine blue stained ( $1 \%$ in $\mathrm{H}_{2} \mathrm{O}$ ) and observed in light microscopy.

\section{TUNEL staining}

TUNEL is a method of choice for a rapid identification and quantification of apoptotic cells. DNA strand breaks, yielded during apoptosis, can be identified by labeling free $3^{\prime}-\mathrm{OH}$ termini with modified nucleotides in an enzymatic reaction. Paraffin embedded tissue sections (9 $\mu \mathrm{m}$ ) dewaxed, rehydrated and preincubated with Proteinase $\mathrm{K} 20 \mu \mathrm{g} / \mathrm{mL}$ in $10 \mathrm{mmol} / \mathrm{L}$ Tris- $\mathrm{HCl} \mathrm{pH}$ 7.6, were exposed to TUNEL mixture, according to illustration sheet (Boehringer Mannheim, Germany). After two rinses in PBS, slides were mounted by using a propidium iodide-glycerol solution $(10 \mu \mathrm{g} / \mathrm{mL})$ and analyzed under fluorescent microscope (Leica Cambridge Ltd, Cambridge, UK). Negative control was performed by omitting the incubation in the presence of the enzymatic mixture (not shown).

\section{Immunohistochemistry}

To detect TERT expression, paraffin-embedded tissue sections $(9 \mu \mathrm{m})$ were blocked in PBS, $5 \%$ normal goat serum (NGS), $0.1 \%$ bovine serum albumine (BSA) and $0.1 \%$ Tween-20 for $30 \mathrm{~min}$ at room temperature, and incubated with rabbit TERT polyclonal antibody (1:100) (Santa Cruz Biotechnology inc., Santa Cruz, CA, USA). Sections were incubated in the presence of HRP conjugated biotinylated secondary antibody and Avidin Biotin. Peroxidase was developed by using diaminobenzidine chromogen (DAB) (BIOMEDA Corp., $\mathrm{Ca}$, USA) and nuclei were hematoxilin counterstained. Negative controls were performed by omitting the primary antibody.

\section{Western Blotting analysis}

Total cell lysates $(20 \mu \mathrm{g})$ or immunoprecipitated p53 samples were electrophoresed and transferred to nitrocellulose, as previously described (Cataldi et al., 2004). Nitrocelluloses, blocked in $5 \%$ non-fat milk, $10 \mathrm{mmol} / \mathrm{L}$ Tris $\mathrm{pH} \mathrm{7.5,} 100$ $\mathrm{mmol} / \mathrm{l} \mathrm{NaCl}, 0.1 \%$ Tween-20, were probed with goat polyclonal Caspase-3, rabbit polyclonal p53 and mouse monoclonal HIF-1 $\alpha$ antibodies (1:250) (Santa Cruz, Santa Cruz Biotechnology, CA, USA) and then incubated in the presence of specific enzyme conjugated IgG horseradish peroxidase. Immunoreactive bands were detected by ECL detection system (Amersham Intl., Buckinghamshire, UK) and analysed by densitometry. 
Densitometric values, expressed as Integrated Optical Intensity (I.O.I.), were estimated in a CHEMIDOC XRS system by the QuantiOne 1-D analysis software (BIORAD, Richmond, CA, USA). Values obtained were normalized basing on densitometric values of internal $\alpha$-actin. Data were analyzed using the two tailed, two sample Student $t$ test. Results were expressed as mean \pm SD. Values of $p<0.05$ were considered significant.

\section{Computerized morphometry measurements and image analysis}

After digitizing the images deriving from Toluidine blue stained sections, MetaMorph Software System (Universal Imaging Corporation, Molecular Device Corporation, PA, USA) (Crysel Instruments, Rome, Italy) overlay tools were used to measure interstitial area and myocardial fiber diameters or evaluation of telomerase expression.

Morphometric computerized analysis of interstitial area and myocardial diameters was performed after calibrating the program for the magnification used (100x).

Image analysis of protein expression was performed through the quantification of tresholded area for immunohistochemical brown colours per field of light microscope observation.

MetaMorph assessments were logged to Microsoft Excel and processed for Standard Deviation and Histograms.

\section{Results}

Toluidine blue semithin sections, observed in light microscopy and measured by MetaMorph Software System, reveal in the hypoxic young heart smaller myocardial cells and increased space between them occupied by more abundant vessels, with respect to the normoxic one. No difference is observed between normoxic and hypoxic old heart, which disclose similar features (abundant connective component and cell enlargement) (Figure 1). At the basis of such morphological
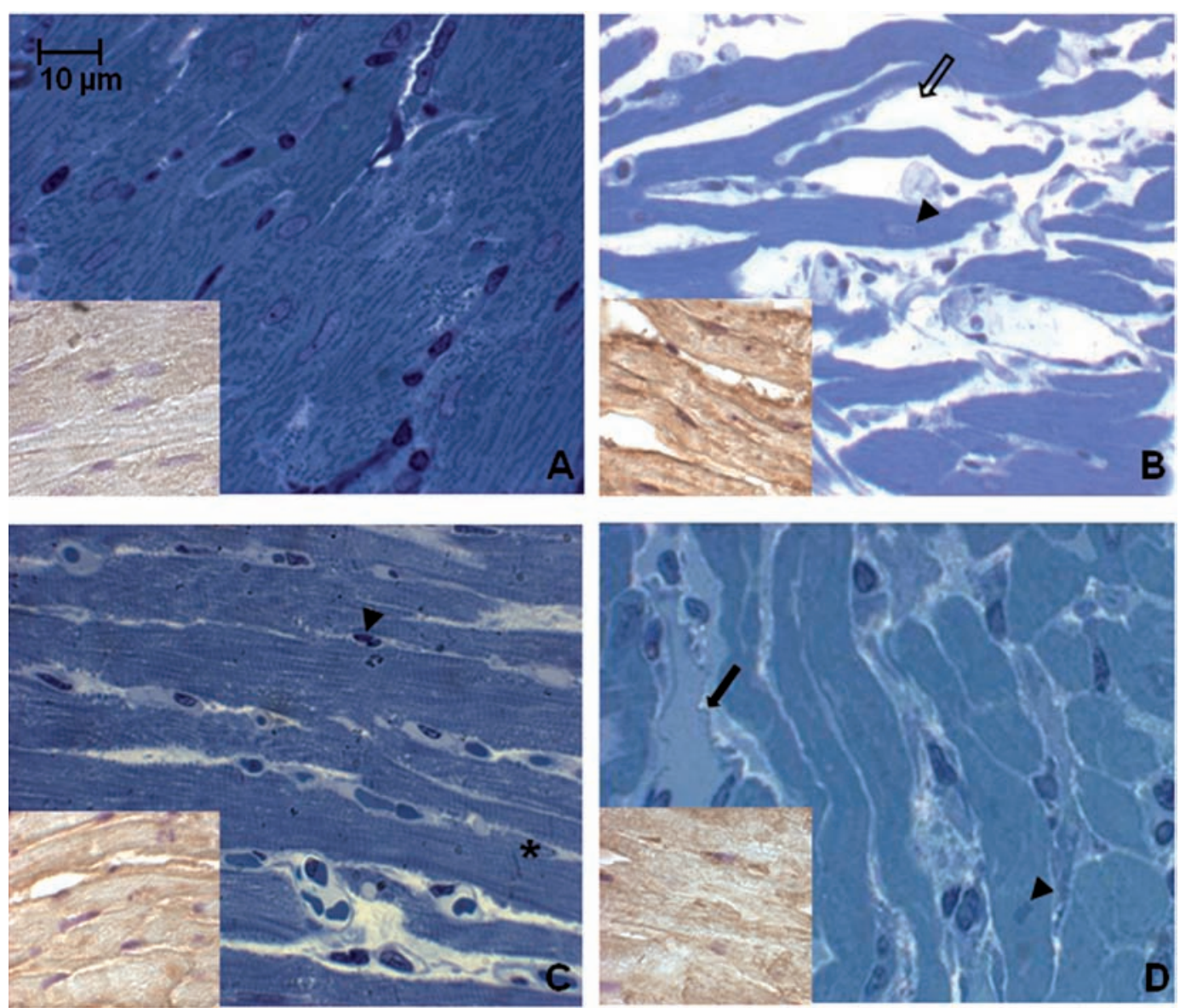

Figure 1. Toluidine blue stained semithin sections of rat heart in different experimental conditions. Note in the hypoxic young smaller cells and increased space (thin arrow) between them occupied by abundant vessels (thick arrows) (A-B). Similar features are disclosed by the old in the two experimental conditions (cell enlargement and abundant connective compartment) (C-D). Arrowheads indicate myocardial cell nuclei. Asterisk indicates intercalated disk. Insets represent myocardial cells positivity to HIF-1 $\alpha$, hypoxic condition marker. (A) normoxic young; (B) hypoxic young; (C) normoxic old; (D) hypoxic old. 

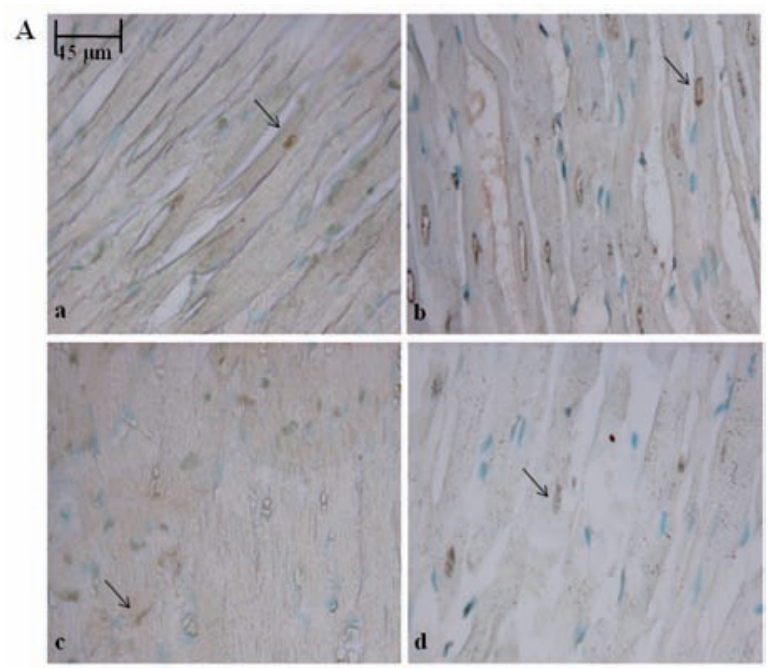

B

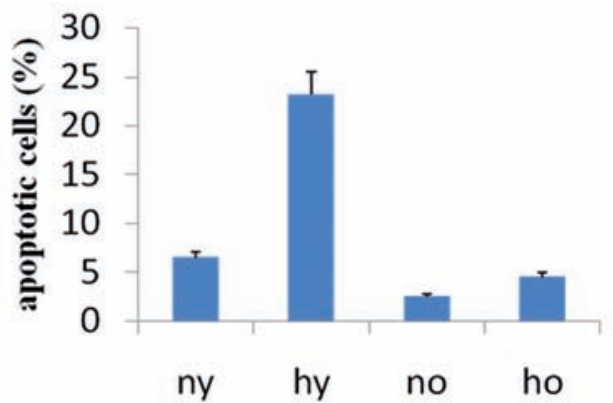

Figure 2. (A) TUNEL analysis of rat heart in different experimental conditions. Green fluorescence labels positive nuclei, red fluorescence labels negative nuclei. The presence of DNA fragmentation was quantified by direct visual counting of fluorescent labelled nuclei. a. normoxic young; b. hypoxic young; $c$. normoxic old; d. hypoxic old. (B) Graphical representation of TUNEL analysis. Five slides were examined per sample. Apoptotic cells were counted out of a total of 100 cells. Values represented in the graph are means \pm SD. $n=3$ for all groups.

modifications, due to senescence and hypoxia, a DNA damage lies. In fact cellular senescence, as well as hypoxic challenge, might cause or contribute to loss of cell proliferative capacity along with apoptosis occurrence. In Figure 2 TUNEL analysis discloses an increased number of myocardial apoptotic cells after hypoxia exposure both in the young and, in the old, even though to a lesser extent. This evidence is supported by an increased level of cleaved caspase-3, which represents one of the molecular mechanisms at the basis of apoptosis occurrence (Figure 3). Being Telomerase expression and activity closely associated to the cell reproductive potential, in Figure 4 a reduced expression of such enzyme both in normoxic and hypoxic old myocardial tissue and in the hypoxic young, with respect to the normoxic young, is evidenced. Figure 5 A-B show p53 increased expres-

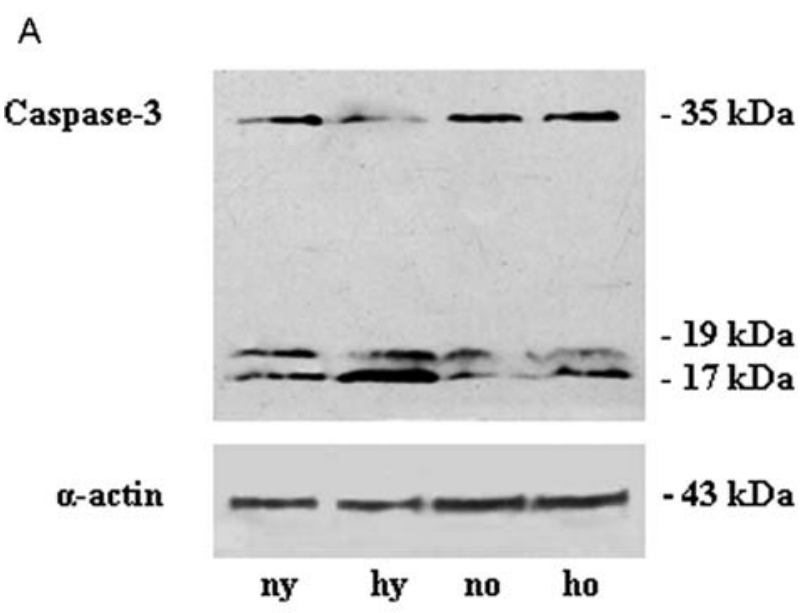

B

Full length $\quad 19 \mathrm{kDa} \quad 17 \mathrm{kDa}$

\begin{tabular}{|l|l|l|l|}
\hline ny & $0.36 \pm 0.02$ & $0.30 \pm 0.03$ & $0.40 \pm 0.04 *$ \\
\hline hy & $0.10 \pm 0.01$ & $0.47 \pm 0.04$ & $1.41 \pm 0.10 *$ \\
\hline no & $0.27 \pm 0.01$ & $0.19 \pm 0.01$ & $0.15 \pm 0.01$ \\
\hline ho & $0.38 \pm 0.02$ & $0.17 \pm 0.01$ & $0.35 \pm 0.02$ \\
\hline
\end{tabular}

Figure 3. (A) Western blotting analysis of cleaved caspase 3 of rat heart in different experimental conditions. The most representative out of three separate experiments is shown. (B) Densitometric analysis of cleaved caspase 3 expression. Quantitative analysis of the protein has been normalised against mouse $\alpha$ sarcomeric actin. Results are the mean of three different experiments \pm SD. ny: normoxic young; hy: hypoxic young; no: normoxic old; ho: hypoxic old *Hypoxic young cleaved caspase-3 vs normoxic young cleaved caspase-3: $p<0.05$.

sion in the young after hypoxia exposure and slightly in both the old subjects, with respect to the normoxic young, in parallel to enhanced level of HIF-1 $\alpha$. Lastly, when immunoprecipitated p53 is probed against HIF-1 $\alpha$, a direct association between HIF-1 $\alpha$ and p53 is found only in the hypoxic young (Figure $5 \mathrm{C}$ ). Interestingly, no modification is observed neither in p53 nor in HIF-1 $\alpha$ level in the old in the two experimental conditions.

\section{Discussion}

Cellular senescence and hypoxia determine the occurrence of an oxidative stress which induces morphological and molecular modifications, lastly leading to exit from the cell cycle and cell death by 
A
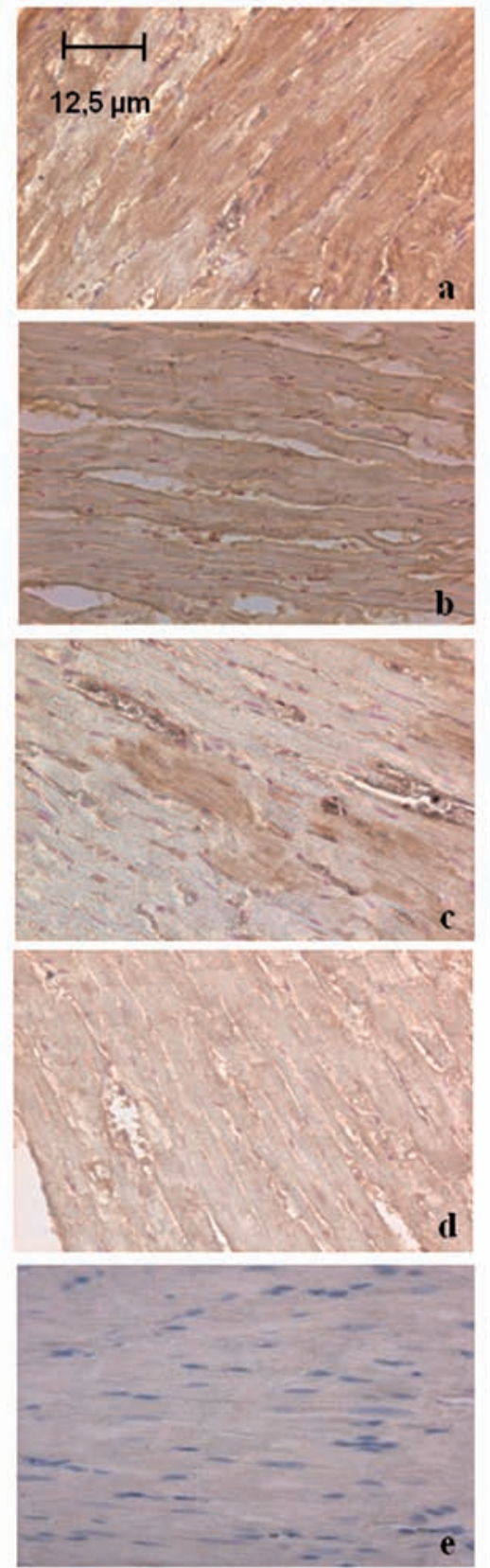

B

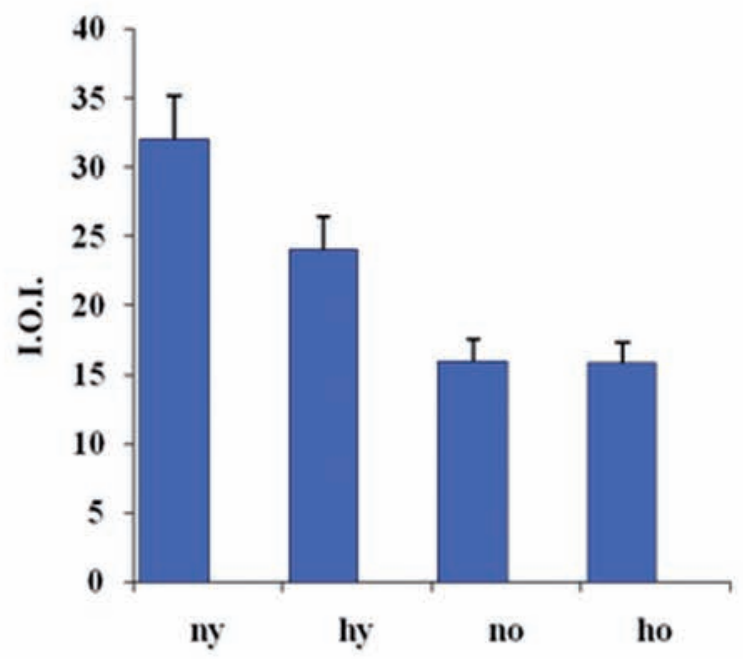

C

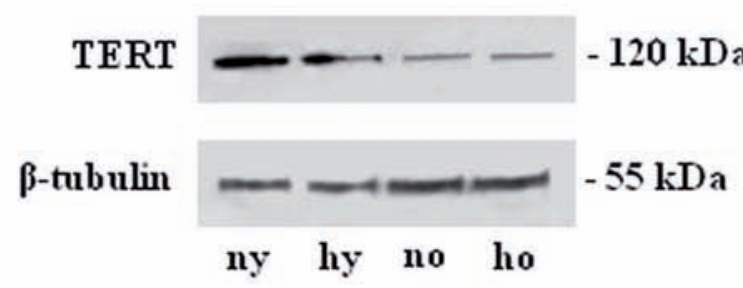

\begin{tabular}{|l|l|}
\hline ny & $0.24 \pm 0.03^{*}$ \\
\hline hy & $0.16 \pm 0.02^{*}$ \\
\hline no & $0.060 \pm 0.01$ \\
\hline ho & $0.063 \pm 0.01$ \\
\hline
\end{tabular}

Figure 4. (A) Immunohistochemical analysis of TERT expression of rat heart in different experimental conditions. The expression of TERT decreases during aging (c) and after hypoxia exposure either in the young either in the old (b, d). (B) Densitometric analysis of TERT positive area \pm SD determined by direct visual counting of three fields for each of five slides per sample. a. normoxic young; $b$. hypoxic young; c. normoxic old; d. hypoxic old; e. negative control. (C) Western blotting analysis of TERT expression. The most representative out of three separate experiments is shown. Blot has been normalised against mouse $\alpha$ sarcomeric actin. ny: normoxic young; hy: hypoxic young; no: normoxic old; ho: hypoxic old *Hypoxic young TERT vs normoxic young TERT: $p<0.05$.

apoptosis (McEachern et al., 2000; Von Zglincki, 2002). The different response depends on the cell type, on the kind and on the level of the stress (Ben-Porath and Weinberg, 2005). Apoptosis during adult and aged life is needed to maintain homeostasis by counterbalancing mitosis and deleting vestigial cells which are potentially immunoreactive, malignant or virus infected. In addition, with age a progressive decline in cell function can be observed, related either to a 


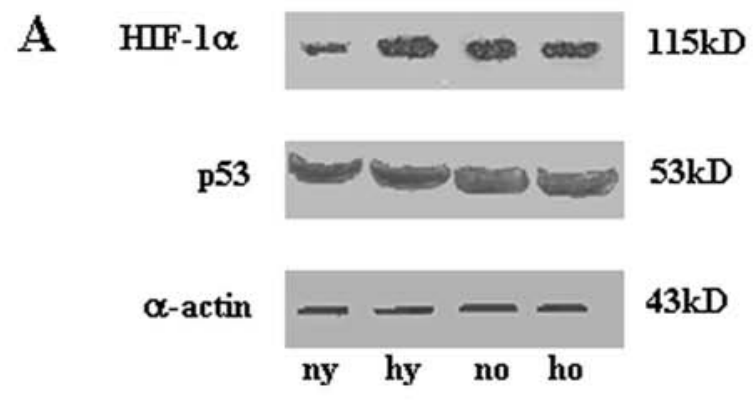

B
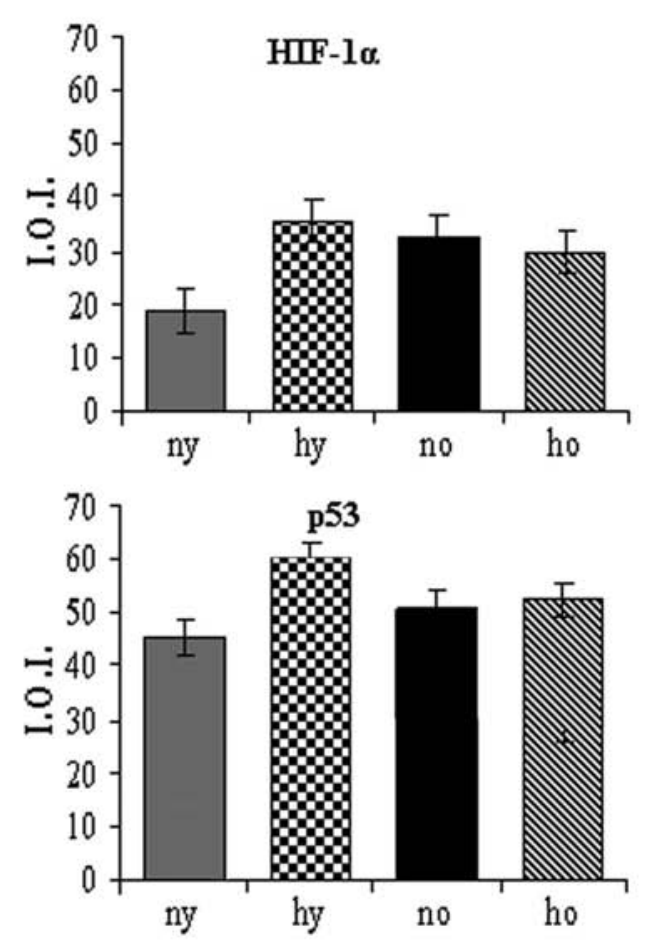

C

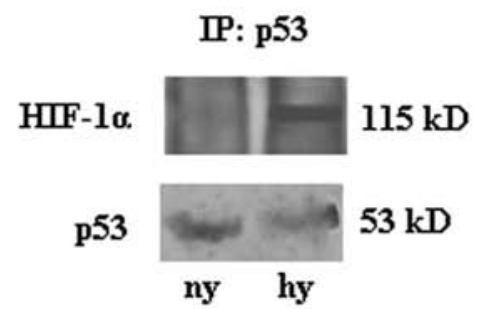

Figure 5. (A) Western blotting analysis of HIF-1 $\alpha$ and p53 expression of rat heart in different experimental conditions. The most representative out of three separate experiments is shown. (B) Densitometric analysis of HIF-1 $\alpha$ and p53 expression. Quantitative analysis of the proteins has been normalised against mouse $\alpha$ sarcomeric actin. Results are the mean of three different experiments \pm SD. Hypoxic young HIF-1 $\alpha$ and p53 vs normoxic young HIF-1 $\alpha$ and p53: $p<0.05$. (C) Effect of hypoxia on direct association of HIF-1 $\alpha$ with p53. p53 was immunoprecipitated (IP) and probed against anti HIF-1 $\alpha$ (top). p53 immunoprecipitation was verified by reprobing against anti-p53 (bottom). ny: normoxic young; hy: hypoxic young; no: normoxic old; ho: hypoxic old. genetic program or to the accumulation of stochastic errors in somatic cells (Camougrand and Rigoulet, 2001). Also hypoxia induces oxidative stress which determines damage to various cell components and triggering of specific signalling pathways. In our experimental model TUNEL analysis reveals an increased number of apoptotic cells in both samples after hypoxia exposure, mainly in the young, with respect to the old. In any case progressive shortening of the telomeres is involved in such responses. Telomeres, in fact, can act as sensors of certain type of DNA damage triggering senescence or, when the damage exceeds a threshold, apoptosis. Dysfunctional telomeres thus determine cellular outcomes, cellular senescence, cell death or genomic instability. Genomic instability predisposes cells to neoplastic transformation, while cellular senescence can be considered tumour suppressive response which prevents the proliferation or survival of cells at risk for developing genomic instability (Campisi et al., 2001). The level of Telomerase expression lowers in the hypoxic young and in the old in both the experimental conditions, with respect to the normoxic young, while no difference is evidenced between the two old experimental conditions, suggesting that such apoptotic response could be ascribed to the progressive shortening of the telomeres, due to reduced telomerase level and activity (Wright and Shay, 2005). This event is paralleled by $\mathrm{p} 53$ and HIF- $1 \alpha$ increased expression and by $\mathrm{p53} / \mathrm{HIF}-1 \alpha$ co-immunoprecipitation in the young after hypoxia exposure, less in the old, in which these proteins are expressed at the same level in normoxic and hypoxic conditions. It should be considered that p53 plays a pivotal role in controlling the occurrence of senescence (Itahana et al., 2001), as well as the response to different stimuli, among which hypoxia is included (Koumenis et al., 2001; Pan et al., 2004), and that HIF-1 $\alpha$ is the enzyme involved in transcriptional, posttranscriptional and posttranslational changes in synthesis of rescue proteins against hypoxia (Carmeliet et al., 1998; Schumacker, 2003, Semenza, 2001, 2004) and during ageing (Cataldi et al., 2004; Bianchi et al., 2006).

The co-immunoprecipitation determines HIF-1 $\alpha$ stabilization, by avoiding rescue proteins production, and induces damage to genomic DNA by ROS production at mitochondrial level (Terman et al., 2004) that accelerates the senescence of cells 
doing so through p53 activation (An et al., 1998; Suzuki et al., 2001).

These results are in accordance with literature concerning human perypheral blood monocytic cells which suggests that telomere length cannot be used unconditionally as a biomarker of ageing process, but telomere instability might be casual for the increased breakdown of telomere length and might be considered as an high biomarker at high age (Martin-Ruiz et al., 2005). On the other hand, indirect evidence of such effect is shown by telomere length maintenance sufficiency to provide replicative capability to human hemopoietic stem cells which determines their transplantation capacity (Allsopp et al., 2003)

Thus all in all our results support four main in vivo evidences:

- the number of muscle cells in the mammalian heart modifies throughout the life and is characterized by ongoing cell death and small capacity for cell regeneration until the senescence occurs; - the excess in cell drop out leads to ventricular de-compensation;

- oxidative stress (i. e. hypoxia) induces different responses during life and the young subject seems to be the most stressed, as revealed by the large number of apoptotic events, with respect to the old, which is adapted to hypoxic environment or has impaired oxygen sensing mechanisms;

- this kind of response implies TERT expression reduction and, by preventing TERT down-regulation, cell cycle exit and apoptosis occurrence could be delayed and new possibilities for interventions against cellular ageing and cell oxidative stress (hypoxia) could be opened.

\section{Acknowledgements}

This work has been supported by 2008 MIUR $60 \%$ grant Prof. A. Antonucci.

\section{References}

Allsopp RC, Morin GB, Horner JW, DePinho R, Harley CB, Weissman IL. Effect of TERT over-expression on the long-term transplantation capacity of hematopoietic stem cells. Nature Medicine 2003; 9:369-71.

An WG, Kanekal M, Simon MC, Maltepe E, Blagosklonny MV, Neckers LM. Stabilization of wild-type $\mathrm{p5} 3$ by hypoxia -inducible factor $1 \alpha$. Nature 1998;392:405-8.

Amundson SA, Myers TG, Fornace AJ. Roles for p53 in growth arrest and apoptosis: putting on the brakes after genotoxic stress. Oncogene 1998;17:3287-99.
Ben-Porath IB, Weinberg RA. When cells get stressed : an integrative view of cellular senescence. J Clin Invest 2004;113:8-13.

Ben-Porath IB, Weinberg RA. The signals and pathways activating cellular senescence. Int J Biochem Cell Biol 2005;37:961-76

Bianchi G, Di Giulio C, Rapino C, Rapino M, Antonucci A, Cataldi A. p53 and p66 proteins compete for Hypoxia-Inducible-Factor 1 alpha stabilization in young and old rat hearts exposed to intermittent hypoxia. Gerontology 2006;52:17-23

Blackburn E. Telomere states and cell fate. Nature 2000; 408: 53-6

Blackburn E. Switching and signalling at the telomere. Cell 2001;106:661-73.

Camougrand N, Rigoulet M. Ageing and oxidative stress: studies of some genes involved both in ageing and in response to oxidative stress. Respir Physiol 2001;128:393-401.

Campisi J, Kim SH, Lin CS, Rubio M. Cellular senescence, cancer and ageing: the telomere connection. Exp Gerontol 2001; 36 :161937.

Carmeliet $P$, Dor $Y$, Herbert JM, Fukumura $D$, Brusselmans $K$, Dewerchin M. et al. Role of HIF-1 $\alpha$ in hypoxia-mediated apoptosis, cell proliferation and tumour angiogenesis. Nature 1998;394: 485-90.

Cataldi A, Bianchi G, Rapino C, Sabatini N, Centurione L, Di Giulio C. et al. Molecular and morphological modifications occurring in rat heart exposed to intermittent hypoxia: role for Protein Kinase C $\alpha$. Exp Gerontol 2004; 39:395-405.

Crow MT, Mani K, Nam YJ, Kitsis RN. The mitochondrial death pathway and cardiac myocyte apoptosis. Circ Res 2004;95:957-70

Fridman JS, Lowe SW Control of apoptosis by p53. Oncogene 2003; 22: 9030-40.

Itahana K, Dimri G, Campisi J. Regulation of cellular senescence by p53. Eur J Biochem 2001;268:2784-91.

Koumenis C, Alarcon R, Hammond E, Sutphin P, Hoffman W, Murphy $M$., et al., Regulation of p53 by hypoxia: dissociation of transcriptional repression and apoptosis from p53-dependent transactivation. Mol Cell Biol 2001;4:1297-310.

Martin-Ruiz CM, Gussekloo J, van Heemst D, von Zglinicki T, Westendorp RGJ. Telomere length in white blood cells is not associated with morbidity or mortality in the oldest old: a populationbase study. Aging Cell 2005;4:287-90.

McEachern MJ, Kranskopf A, Blackburn EH. Telomeres and their control. Annu Rev Genet 2000;34:331-8.

Oh H, Taffet GE, Youker KA, Entman ML, Overbeek PA, Michael LH., et al., Telomerase reverse transcriptase promotes cardiac muscle cell proliferation, hypertrophy and survival. PNAS 2001;98: 10308-13.

$\mathrm{Oh} \mathrm{H}$, Schneider MD. The emerging role of telomerase in cardiac muscle cell growth and survival. J Mol Cell Cardiol 2002;34:71724.

Pan Y, Oprisko PR, Asham AM, Koch CJ, Simon MC. p53 cannot be induced by hypoxia alone but responds to the hypoxic microenvironment. Oncogene 2004;26:4975-83.

Passos JF, Saretzki G, von Zglinicki T. DNA damage in telomeres and mitochondria during cellular senescence: is there a connection? Nucleic Acid Res 2007;35:7505-13.

Rapino C, Bianchi G, Di Giulio C, Centurione L, Cacchio M, Antonucci $A$, et al. HIF-1 alpha cytoplasmic accumulation is associated with cell death in old rat cerebral cortex exposed to intermittent hypoxia. Aging Cell 2005;4:177-85.

Rubio MA, Davalos AR, Campisi J. Telomere length mediates the effects of telomerase on the cellular response to genotoxic stress. Exp Cell Res 2004;298:17-27.

Sager R. Senescence as a mode of tumour suppression. Environ Health Persp 1991;93:59-62.

Schumacker PT. Current paradigms in cellular oxygen sensing. Adv Exp Med Biol 2003;543:57-71.

Semenza GL. HIF-1 and mechanisms of hypoxia sensing. Curr Opin Cell Biol 2001;13:167-71.

Semenza GL. Hydroxylation of HIF-1: oxygen sensing at the molecular level. Physiology 2004;19:176-82.

Sharpless NE, DePinho RA. Telomeres, stem cells, senescence and cancer. J Clin Invest 2004;113:160-8. 


\section{A. Cataldi et al.}

Smogorzewska A, de Lange T. Different telomere damage signalling pathways in human and mouse cells. EMBO J 2002;21: 4338-48

Suzuki H, Tomida A, Tsurno T. De-phosphorylated HIF-1 $\alpha$ as a mediator of p53 dependent apoptosis during hypoxia. Oncogene 2001; 20:5779-88.

Terman A, Dalen H, Eaton JW, Neuzil J, Brunk UT. Aging of cardiac myocytes in culture. Oxidative stress, lipofuscin accumulation and mitochondrial turnover. Ann N Y Acad Sci 2004;1019:70-7.

Torella D, Rota M, Nurzynska D, Musso E, Monsen A, Shiraishi I., et al., Cardiac stem cell and myocyte ageing, heart failure and insulin-like growth factor over-expression. Circ Res 2004; 94: 514-24.

Von Zglincki T. Oxidative stress shortens telomeres. TRENDS Biochem Sci 2002;27:339-44.

Wright WE, Shay JW. Telomere biology in ageing and cancer. J Am Geriatr Soc 2005;53:S292-4. 